\title{
The COVID-19 pandemic in Japan: Its impact on a newborn's childcare environment and on the mother's sense of loneliness
}

\section{Ai Miyoshi}

Osaka University Graduate School of Medicine

Yutaka Ueda ( $\sim$ ZVF03563@nifty.ne.jp)

Osaka University Graduate School of Medicine

Mariko Taniguchi

Osaka University Graduate School of Medicine

Asami Yagi

Osaka University Graduate School of Medicine

\section{Toshihiro Kimura}

Osaka University Graduate School of Medicine

\section{Eiji Kobayashi}

Osaka University Graduate School of Medicine

\section{Kosuke Hiramatsu}

Osaka University Graduate School of Medicine

\section{Satoshi Nakagawa}

Osaka University Graduate School of Medicine

\section{Tsuyoshi Takiuchi}

Osaka University Graduate School of Medicine Hitomi Arahori

Osaka University Graduate School of Medicine

\section{Sayaka Ikeda}

Osaka University Graduate School of Medicine

Kei Hirai

Osaka University

\section{Tadashi Kimura}

Osaka University Graduate School of Medicine

\section{Research Article}

Keywords: COVID-19, pandemic; loneliness, social isolation, young children 
Posted Date: May 20th, 2021

DOl: https://doi.org/10.21203/rs.3.rs-490333/v1

License: (c) (i) This work is licensed under a Creative Commons Attribution 4.0 International License. Read Full License 
The COVID-19 pandemic in Japan: Its impact on a newborn's childcare environment and on the mother's sense of loneliness

Ai MIYOSHI ${ }^{1}$, Yutaka UEDA ${ }^{1}$, Mariko TANIGUCHI ${ }^{1}$, Asami YAGI $^{1}$, Toshihiro KIMURA ${ }^{1}$, Eiji KOBAYASHI ${ }^{1}$, Kosuke HIRAMATSU ${ }^{1}$, Satoshi NAKAGAWA ${ }^{1}$, Tsuyoshi TAKIUCHI ${ }^{1}$, Hitomi ARAHORI ${ }^{2}$, Sayaka IKEDA ${ }^{3}$, Kei HIRAI $^{4}$, Tadashi KIMURA ${ }^{1}$

Affiliations: 1) Department of Obstetrics and Gynecology, Osaka University Graduate School of Medicine, Osaka, Japan

2) Department of Pediatrics, Osaka University Graduate School of Medicine, Osaka, Japan

3) Department of Social Environmental Medicine, Osaka University Graduate School of Medicine, Osaka, Japan

4) Clinical Psychology, Graduate School of Human Science, Osaka University, Osaka, Japan

To whom correspondence should be sent:

Yutaka Ueda, MD, $\mathrm{PhD}$

Department of Obstetrics and Gynecology, Osaka University Graduate School of Medicine, 2-2, Yamadaoka Suita, Osaka 567-0871, Japan

Phone: 81-6-6879-3351; Fax: 81-6-6879-3359; E-mail: ZVF03563@nifty.ne.jp 


\begin{abstract}
Background: The COVID-imposed social isolation of Japanese mothers has significantly increased their already existing sense of loneliness. We report here on the changes that have occurred in the environment of home childcare and in the mother's feelings of loneliness during the pandemic and we compare these findings with results from a similar previous study we conducted in 2019.
\end{abstract}

Methods: In 2019, we conducted an online survey of mothers who had infants aged 4-12 months. Many of the survey questions at that time concerned the home childcare environment and the mother's sense of loneliness. In 2020, during the height of this COVID pandemic, we conducted a follow-up COVID impact survey using the same questionnaire, of a different group mothers, again having infants of 4-12 months, to determine the impact of the pandemic on the mothers of extra-vulnerable young children.

Results: The number of women who consulted with their friends or neighbors about childcare during the pandemic had decreased from the more normal times of early 2019 , whereas in 2020 there was an increase in the number who consulted with their mother. The mother's method of gathering childrearing information had shifted away from the face-to-face focus of 2019 to a habit of calling a municipal health center or using social-networking-services (SNS) as a reference. The rate was decreased of a mothers' frequency of interaction with other parents having children at home as old as their own child. Overall, the number of mothers who felt loneliness was significantly increased.

Conclusions: Because of the impact on mothers of the COVID pandemic, specifically around their methods of gathering information concerning childcare, we found that the child-rearing 
environment in Japan has detrimentally changed since early 2019. Whether or not the mother felt stressed or felt they lacked sufficient information concerning childcare was associated with having an impact on the mother's sense of loneliness. The importance of the appropriate transmission of information concerning childcare had increased due to this pandemic, so we need to take aggressive actions to help these mothers of small children to prevent harm and tragedies from occurring to the children in their care.

Keywords: COVID-19; pandemic; loneliness; social isolation; young children 


\section{Background}

There is a growing feeling of isolation among mothers raising very young children that is becoming a serious social problem in Japan. Mothers having a high degree of loneliness are more likely to be depressed and to have decreased self-esteem and poor health, which consequently leads to the poor health of their children and to a rise in child abuse [1]. Official statistics in Japan have shown that one-third of our families now have a small-nuclear structure, rather than the extended-family structure of the past, and $7.0 \%$ of families were fatherless [2]. The time spent doing childcare by Japanese fathers with children younger than 6-years is the lowest among many countries [3-5]. In Japan, the small-nuclear family is slowly becoming the predominant family structure. With increasingly weaker family connections regionally, good information concerning childcare is often sparse and difficult to gather. That has led to societal concerns about the mother's sense of loneliness in raising her children.

In Japan, the COVID-19 pandemic broke out early in the spring of 2020. The pandemic has been almost relentless and has had a huge impact on all our different lifestyles. The pandemic has led Japan to declare a state of public health emergency, with most Japanese taking active preventative measures against infection by wearing a mask, disinfecting their hands, refraining from going out if not necessary and not socializing in person with friends or out-of-household family. Thus, a significant degree of social isolation has developed and it is easily to presume that the 'normal' sense of loneliness any new mother suffers has grown only deeper as the pandemic has been prolonged.

Social isolation for children and loneliness for adolescents have been reported to be linked to an increased risk of depression and possibility of anxiety as late as 9 years later. The duration of 
the loneliness had a stronger correlation with later adverse mental health symptoms than did the acute intensity of the loneliness [6].

We report here on the changing environment of childcare and the mother's sense of loneliness during the first pandemic year of 2020 and we compared these results with those we obtained in 2019. We warn that the potential societal harm to young children requires immediate societal and professional actions to mitigate that harm.

\section{Method}

On January 29th and 30th of 2019, we conducted an online survey of Japanese mothers listed in an internet survey panel as having an infant 4-12 months of age at the time the survey was taken. Valid survey answers were obtained from 412 respondents. The survey questionnaire had several sections, consisting of questions regarding the mother's background (the age of the mother, her current employment, household income, level of economic anxiety, whether she had co-habiting family members, and whether or not the child was her first), the status of their childcare (whether there was anyone else helping her with the childcare, whether there was anyone who she could consult with easily about raising her child/children, and whom did she consult with about raising her child), their methods of gathering information about child healthcare and childrearing, the mother's personal sense of loneliness, whether she was satisfied with her current childcare environment, and how often she interacted with other parents having children of similar age to her child (Other details of this study will be described elsewhere). Just 22 months later, on November 18th and 19th of 2020, we re-conducted the same survey to determine the detrimental effects of the COVID-19 pandemic shutdown on the new-mother's 
perceived loneliness and the childcare environment she felt she was providing. Valid survey answers were obtained from 618 mothers. We reused the 2019.

\section{Statistics}

Using StatsModels, differences between the two groups were calculated by the chi-square test and the logistic regression test for categorical variables. The level of statistical significance was set at $\mathrm{p}=0.05$.

\section{Results}

Characteristics of the internet survey responders

The relevant characteristics of the responders in the two survey years of Jan 2019 and Nov 2020 are shown in Table 1. No statistically significant differences existed between the characteristics of the two respondent groups.

Q. - Do you have someone who can be easily consulted with about raising your child? In $2019,87.9 \%$ of the mothers answered that they had someone and $12.1 \%$ answered that they did not. In 2020, $84.0 \%$ answered yes. Mothers thus tended to have lost a person who could be easily consulted with about raising her child (Table 2).

Q. - Whom do you consult with about raising your child?

Back in 2019, 71.8\% of the mothers answered that they consulted with their mother; in 2020, now $78.2 \%$ gave that answer, which was a significant increase ( $\mathrm{p}=0.029)$ (Figure 1). In 2019, 
$64.6 \%$ of the mothers consulted with their friends, whereas 53.8\% gave that answer in 2020, a significant decrease ( $\mathrm{p}=0.001$ ) (Figure 1). In 2019, $11.0 \%$ of mothers answered that they consulted with their neighbors, but in 2020 it was only $5.4 \%$ of the answers, a significant decrease $(\mathrm{p}=0.002)$ (Figure 1$)$.

Q. - What methods do you use for gathering information about child-rearing?

$27.7 \%$ of the mothers visited a municipal contact for gathering information about raising their child in 2019 and $10.4 \%$ in 2020, a significant decrease ( $<<0.001)$ (Table 3). It was a municipal health center that $5.8 \%$ of the mothers called in 2019 and $11.2 \%$ in 2020 a significant increase $(\mathrm{p}=0.003)$ (Table 3). Social networking services (SNS) were used by $2.9 \%$ of the mothers as a reference for gathering information about child raising in 2019, whereas $34.8 \%$ used it in 2020 , a significant increase $(\mathrm{p}<0.001)$. (Table 3$)$.

Q. - How often do you interact with parents having children the same age as your child? In $2019,4.1 \%$ of mothers were interacting with other parents having children as old as their own child five times or more per week, 6.8\% interacted 3-4 times per week, $18.0 \%$ interacted 1 2 times per week, $26.2 \%$ interacted 1-2 times per month and $44.9 \%$ interacted less than $1-2$ times per month. In 2020, $2.3 \%$ of mothers interacted with other parents having children as old as their own child 5 times or more per week, 3.9\% interacted 3-4 times per week, $14.4 \%$ interacted 1-2 times per week, $14.7 \%$ interacted 1-2 times per month and $64.7 \%$ interacted less than 1-2 times per month. The rate in all categories of interaction-frequency was decreased significantly $(\mathrm{p}<0.001)$ (Table 4$)$. 
Q. - What is your sense of loneliness?

In $2019,56.5 \%$ of the mothers surveyed felt loneliness when raising her own child, $26.0 \%$ did not feel loneliness, and $17.5 \%$ did not answer the question. In $2020,61.8 \%$ of mothers felt loneliness, $27.0 \%$ did not, and $11.2 \%$ did not answer. The number of mothers who felt loneliness increased significantly $(\mathrm{p}<0.05)($ Table5).

Q. - What was the correlation between any changes in childcare environment during the COVID-19 pandemic and the mother's sense of loneliness?

Multivariate analysis for correlations between the changing of the childcare environment during the COVID-19 pandemic and the mother's sense of loneliness revealed that whether or not the mother felt stressful ( $p<0.0001$, increased odds ratio:4.19, 95\%CI:2.73 6.43) and whether or not she felt she lacked sufficient information concerning childcare $(\mathrm{p}=0.004$, increased odds ratio:2.65, 95\%CI:1.36 5.14) were associated with an impact on the mother's sense of loneliness (Table 6).

Q. - What was the mother's sense of satisfaction with her childcare environment? In $2019,57.8 \%$ of the mothers surveyed were satisfied with their childcare environment. This sense of satisfaction increased significantly, to 65.6\%, in $2020(\mathrm{p}=0.013)$ (Table 7). Multivariate analysis of the correlation between the changing of her childcare environment during the COVID-19 pandemic and her satisfaction with her childcare environment revealed that less economic anxiety ( $\mathrm{p}=0.01$, increased odds ratio:0.445, 95\%CI:0.24 0.83), the presence 
of someone to help raise her child ( $\mathrm{p}=0.0001$, increased odds ratio:2.79, 95\%CI:1.66 4.67), and the presence of someone who could be easily consulted ( $\mathrm{p}<0.0001$, increased odds ratio:3.63, 95\% CI:2.02 6.51), were each associated with a positive improvement on the presence of the mother's sense of loneliness (Table 8).

\section{Discussion}

During this ongoing COVID-19 pandemic, mothers in Japan have not significantly lost people whom they can easily consult with about raising their child, but the type of person whom mothers have been consulting with has changed significantly. In 2019, most mothers were consulting with their primary partner about raising their child. In contrast, during the pandemic year of 2020, the frequency with which new mothers consulted with their neighbors or friends had dropped significantly, and the person whom they now consulted with the most had shifted to their own mother. There was also a parallel shift in the methods of gathering child-rearing information, away from face-to-face information gathering to now visiting municipal contacts, in particular to calling municipal health centers and to using SNS as a reference for SARS-CoV2 infection prevention.

The frequency of the mother's interactions with other parents having children as old as her own child was also increased significantly. Before the COVID-19 pandemic, mothers often interacted with other parents having children the same age as her own child at a child support center or on the way to and from a childcare center. They could obtain childcare information and release stress at the same time. However, the declaration of a state of emergency caused childcare centers and elementary schools to be closed, work attendance was regulated, and 
staying by at home was recommended. They had dramatically lost the opportunity for personal peer interactions and felt more stressed as a result.

The percentage of mothers who felt lonely has increased significantly during the COVID-19 pandemic. Mandai et al. reported that the mother's sense of loneliness was also significantly associated with being financially worse-off, having a smaller family social network, having fewer friends, and having a smaller SNS network [7], thus it is highly relevant that COVID-19 has robbed many mothers of their financially security, their family social networks, and their contact with friends.

We evaluated the causes of the mother's increased sense of loneliness during the COVID-19 pandemic in a way that allows us to draw a comparison between two periods, one immediately before and the other during the COVID-19 pandemic. The increased burden of housekeeping and childcare, an economic anxiety from losing job opportunities and fulfilments, the lack of information concerning childcare, and the novel difficulties surrounding modern childcare were all associated with the mother's sense of stress and loneliness. These factors' impact on the mother's sense of loneliness was confirmed by multivariate analysis.

During the prolonged pandemic, the accompanying reduced social networks and stressful feelings couldn't be easily helped because of the need for maintaining COVID-19 social distancing, even though loneliness was clearly adverse for the mother, her small children and for adolescents. However, it still may be possible for society to resolve the lack of childrearing information.

Chen et al. have reviewed the positive effects of information communication technology (ICT) for interventions that reduce social isolation in the elderly. ICT use was consistently found to 
positively affect social support, social connectedness, and social isolation in general. They assessed the mechanisms for the positive effect of ICT and it was found to be the result of connecting to the outside world, gaining social support, engaging in activities of interests, and boosting self-confidence [8-11].

Blažun et al. found that Slovene participants at nursing homes reported no change of loneliness level after their use of Skype videoconferencing [12], while the loneliness of Taiwanese nursing home participants was significantly lessened after their use of Skype or Windows Live Messenger [13.14]. Sum et al. reported that computer and Internet use functioned differently for various types of loneliness: social loneliness, family loneliness, and romantic loneliness. Using computers and the Internet to communicate with acquaintances alleviated elderly people's social loneliness, whereas using the computer and Internet to make new contacts resulted in family loneliness [15].

As above, ICT has the potential to resolve the lack of information concerning childcare and also alleviate the mother's feelings of isolation and loneliness. As a result, the importance of transmission of information concerning childcare had been increased. We need to rapidly think of new ways to send information, including Skype, SNS, Instagram, and so on. Unexpectedly, given what we found for other aspects of the newborn's mother's lives, mothers in 2020 seemed more satisfied with their childcare environment than in 2019. We assessed some of the factors associated with this sense of satisfaction, which revealed that the mothers were feeling less economic anxiety, they felt they had someone else who was helping them raise their child, and they had someone who could be easily consulted about raising their child. These feelings were all significantly associated with their sense of satisfaction with the child rearing 
environment they were providing. A sense of anxiety toward COVID-19 infection was not associated with their child-rearing satisfaction. In what would normally be seemingly an inconvenient lifestyle during the COVID-19 pandemic, mothers in Japan have had a change of heart, now finding that small things, such as having helping hand to raise her child and someone to easily consult with about child-raising, could lead to improved satisfaction with their own child-raising environment.

Our study does have several limitations. First, other studies use a formal index, such as the revised UCLA Loneliness Scale, to evaluate the 'sense of loneliness'. However, in our study, it was difficult to accurately compare our survey results to such a formal classification system because we only questioned the mothers as to self-evaluate whether they had a sense of loneliness. Second, i was not at all clear that the many changes in the mother's lifestyle, childcare environment and feelings were all direct effects caused by the COVID-19 pandemic. It's possible that the interpersonal communication tools have changed between the times of the two surveys, although the interval was only 22 months. Lastly, we have not investigated whether any changes of the mother's lifestyle, childcare environment or feelings have caused adverse effects to their children or actual harm beyond the sense of isolation to the mother.

\section{Conclusions}

Our recent survey has found that, because of the social impacts of the COVID-19 pandemic on Japanese mothers, their childcare environment and their methods of gathering childcare information have changed. Mothers have felt an increased loneliness while child raising. Feelings of stress and a perceived lack of information about childcare were associated with their 
sense of loneliness. Our study highlights the importance of rapidly improving the transmission of information concerning childcare in fighting a newborn mother's sense of loneliness.

\author{
Abbreviation \\ COVID: Coronavirus Disease, SARS-CoV: Severe Acute Respiratory Syndrome- Coronavirus, \\ SNS: social-networking-services, ICT: information communication technology, UCLA: \\ University of Calfornia, Los Angels
}

\title{
Declarations
}

\section{Ethics approval and consent to participate}

This study was approved by the Institutional Review Board and the Ethics Committee of the Osaka University Hospital (\#14361). The researchers obtained informed consent from participants of the survey on the questionnaire. We included only those who consented to participate. All methods were carried out in accordance with relevant guidelines and regulations.

\section{Consent for publication}

Not applicable.

\section{Availability of data and materials}

All data generated or analyzed during this study are included in this published article. 


\section{Competing interest}

The authors have no conflict of interest relevant to this article.

\section{Funding}

There is no funding.

\section{Authors' contributions}

A.M. : writing manuscript, study design, interpretation of result, Y.U. : study design, interpretation of result, M.T. : sample preparation, A.Y. : sample preparation, T.K. : sample preparation, E.K. : sample preparation, K.H. : sample preparation, S.N. : sample preparation, T.T. : sample preparation, H.A. sample preparation, S.I. : sample preparation, K.H. : sample preparation, T.K. : sample preparation

\section{Acknowledgments}

We would like to thank Dr. G.S. Buzard for his constructive critique and editing of our manuscript.

\section{References}

1. Chung EK, McCollum KF, Elo IT, Lee HJ, Culhane JF. Maternal depressive symptoms and infant health practices among low-income women. Pediatrics. 2004;113:e523-9. 
2. Ministry of Health, Labour and Welfare [Internet].

https://www.mhlw.go.jp/toukei/saikin/hw/k-tyosa/k-tyosa19/dl/14.pdf. [last reviewed Apr 14, 2021].

3. Gender Equality Bureau Cabinet Office. [Internet].

https://www.gender.go.jp/about_danjo/whitepaper/r02/zentai/html/column/clm_01.html [last reviewed Apr 14, 2021].

4. Eurostat [Internet]. http://ec.europa.eu/eurostat/en/web/products-pocketbooks/-/KS-58-04998 (2004). [last reviewed Apr 14, 2021].

5. Bureau of Labor Statistics [Internet]. http://www.bls.gov/tus/ (2016) [last reviewed Jun 29, 2018].

6. Loades ME, Chatburn E, Higson-Sweeney N, Reynolds S, Shafran R, Brigden A, Linney C, McManus MN, Borwick C, Crawley E. Rapid systematic review: The impact of social isolation and loneliness on the mental health of children and adolescents in the context of COVID-19. J Am Acad Child Adolesc Psychiatry. 2020;59:1218-1239.e3.

7. Mandai M, Kaso M, Takahashi Y, Nakayama T. Loneliness among mothers raising children under the age of 3 years and predictors with special reference to the use of SNS: a communitybased cross-sectional study. BMC Womens Health. 2018;18:131.

8. Cattan M, Kime N, Bagnall A. The use of telephone befriending in low level support for socially isolated older people-an evaluation. Health Soc Care Community. 2011;19:198-206.

9. Cotten SR, Anderson WA, McCullough BM. Impact of internet use on loneliness and contact with others among older adults: cross-sectional analysis. J Med Internet Res. 2013;15:e39. 
10. Karimi A, Neustaedter C. From high connectivity to social isolation: communication practices of older adults in the digital age. Computer Supported Cooperative Work; February 11-15, 2012; Seattle WA. Association for Computing Machinery; 2012.

11. Khvorostianov N, Elias N, Nimrod G. 'Without it I am nothing': The internet in the lives of older immigrants. New Media \& Society. 2011;14:583-599.

12. Blažun H, Saranto K, Rissanen S. Impact of computer training courses on reduction of loneliness of older people in Finland and Slovenia. Computers Hum Behav. 2012;28:12021212.

13. Tsai HH, Tsai YF, Wang HH, Chang YC, Chu HH. Videoconference program enhances social support, loneliness, and depressive status of elderly nursing home residents. Aging Ment Health. 2010;14:947-954.

14. Tsai HH, Tsai YF. Changes in depressive symptoms, social support, and loneliness over 1 year after a minimum 3-month videoconference program for older nursing home residents. J Med Internet Res. 2011;13:e93.

15. Sum S, Mathews RM, Hughes I, Campbell A. Internet use and loneliness in older adults. Cyberpsychol Behav. 2008;11:208-211.

\section{Figure legend}

Fig.1 Whom she consult with about raising her child

Back in 2019, 71.8\% of the mothers answered that they consulted with their mother; in 2020, now $78.2 \%$ gave that answer, which was a significant increase ( $\mathrm{p}=0.029)$. In $2019,64.6 \%$ of the mothers consulted with their friends, whereas $53.8 \%$ gave that answer in 2020, a significant 
decrease $(\mathrm{p}=0.001)$. In $2019,11.0 \%$ of mothers answered that they consulted with their neighbors, but in 2020 it was only $5.4 \%$ of the answers, a significant decrease $(\mathrm{p}=0.002)$.

\section{Tables}

Table 1. Characteristics of internet survey responders

\begin{tabular}{|c|c|c|c|}
\hline & 2019 & 2020 & $p$-value \\
\hline Subjects & 412 & 618 & \\
\hline Employment status & & & n.s. \\
\hline company employee (other) & $33(8.0 \%)$ & $45(7.3 \%)$ & \\
\hline part-time staff & $36(8.8 \%)$ & $36(5.8 \%)$ & \\
\hline stay-at-home & $339(82.3 \%)$ & $536(86.7 \%)$ & \\
\hline other & $4(0.9 \%)$ & $1(0.233 \%)$ & \\
\hline Age & $31.9(19 \sim 44)$ & $31.7(21 \sim 44)$ & n.s. \\
\hline Cohabitating family (except for child) & & & n.s. \\
\hline None & $2(0.5 \%)$ & $1(0.2 \%)$ & \\
\hline One & $352(85.4 \%)$ & $549(88.8 \%)$ & \\
\hline Two or more & $58(14.1 \%)$ & $68(11.0 \%)$ & \\
\hline Household income & & & n.s. \\
\hline$<2$ million yen & $9(2.6 \%)$ & $10(2.0 \%)$ & \\
\hline 2-4 million yen & $89(26.0 \%)$ & $103(20.8 \%)$ & \\
\hline 4-6 million yen & $113(33.0 \%)$ & $158(31.9 \%)$ & \\
\hline $6-8$ million yen & $52(15.2 \%)$ & $96(19.4 \%)$ & \\
\hline 8-10 million yen & $23(6.7 \%)$ & $48(9.7 \%)$ & \\
\hline$>10$ million yen & $8(2.4 \%)$ & $34(6.8 \%)$ & \\
\hline unknown & $118(31.0 \%)$ & $169(29.2 \%)$ & \\
\hline
\end{tabular}

Table 2. The presence of a person who can be easily consulted

\begin{tabular}{|lccc|}
\hline & $\mathbf{2 0 1 9}$ & $\mathbf{2 0 2 0}$ & $\boldsymbol{p}$-value \\
\hline The presence of a person who can be easily consulted & 0.086 \\
\hline Yes & $362(87.9 \%)$ & $519(84.0 \%)$ & \\
No & $50(12.1 \%)$ & $99(16.0 \%)$ & \\
Total & $412(100 \%)$ & $618(100 \%)$ & \\
\hline
\end{tabular}


Table 3. Methods of gathering information about child-raising

\begin{tabular}{|lccc|}
\hline & $\mathbf{2 0 1 9}$ & $\mathbf{2 0 2 0}$ & $\boldsymbol{p}$-value \\
\hline Subjects & 412 & 618 & \\
\hline Asked their parents & $271(65.8 \%)$ & $407(65.9 \%)$ & 0.98 \\
Looked at the Web & $394(95.6 \%)$ & $584(94.5 \%)$ & 0.42 \\
Asked their friends & $210(51.0 \%)$ & $311(50.3 \%)$ & 0.84 \\
Visited municipal contacts & $114(27.7 \%)$ & $64(10.4 \%)$ & $<\mathbf{0 . 0 0 1}$ \\
Called municipal health center & $24(5.8 \%)$ & $69(11.2 \%)$ & $\mathbf{0 . 0 0 3}$ \\
Used SNS as a reference & $12(2.9 \%)$ & $215(34.8 \%)$ & $<\mathbf{0 . 0 0 1}$ \\
Asked an unspecified person & $30(7.3 \%)$ & $44(7.1 \%)$ & 0.92 \\
Other & $5(1.2 \%)$ & $11(1.8 \%)$ & 0.47 \\
\hline
\end{tabular}

Table 4. How often did the mother interact with other parents having children the same age as

their child?
\begin{tabular}{|lccc|}
\hline & $\mathbf{2 0 1 9}$ & $\mathbf{2 0 2 0}$ & p-value \\
\hline Frequency & & $<0.001$ \\
\hline 5 times or more per week & $17(4.1 \%)$ & $14(2.3 \%)$ & \\
3 4 times per week & $28(6.8 \%)$ & $24(3.9 \%)$ & \\
$1 \sim 2$ times per week & $74(18.0 \%)$ & $89(14.4 \%)$ & \\
$1 \sim 2$ times per month & $108(26.2 \%)$ & $91(14.7 \%)$ & \\
Less than 1 2 times per month & $185(44.9 \%)$ & $400(64.7 \%)$ & \\
Total & $412(100 \%)$ & $618(100 \%)$ & \\
\hline
\end{tabular}


Table 5. Changes in the mother's sense of loneliness while raising a newborn

\begin{tabular}{|lccc|}
\hline \multicolumn{2}{|c|}{$\mathbf{2 0 1 9}$} & $\mathbf{2 0 2 0}$ & $\boldsymbol{p}$-value \\
\hline \multicolumn{2}{|c|}{ The mother's sense of Ioneliness } & & $<0.05$ \\
\hline Yes & $233(56.5 \%)$ & $382(61.8 \%)$ & \\
No & $107(26.0 \%)$ & $167(27.0 \%)$ & \\
NA & $72(17.5 \%)$ & $69(11.2 \%)$ & \\
Total & $412(100 \%)$ & $618(100 \%)$ & \\
\hline
\end{tabular}

Table 6. Mulrivariate analysis of the correlations between factors associated with the changing of her childcare environment during the COVID-19 lockdown and the mother's sense of loneliness

\begin{tabular}{lccc}
\hline \multicolumn{1}{c}{ Covariate } & Odds Ratio & $\mathbf{9 5 \%}$ C.I. & p-value \\
\hline $\begin{array}{l}\text { Feeling stressed } \\
\begin{array}{l}\text { Increased burden of house } \\
\text { keeping }\end{array}\end{array}$ & $\mathbf{4 . 1 9}$ & $\mathbf{2 . 7 3}$ to $\mathbf{6 . 4 3}$ & $<\mathbf{0 . 0 0 0 1}$ \\
$\begin{array}{l}\text { Increased burden of raising } \\
\text { children }\end{array}$ & 1.35 & 0.66 to 2.01 & 0.63 \\
$\begin{array}{l}\text { Economic anxiety } \\
\text { Lacking of information }\end{array}$ & $\mathbf{2 . 6 5}$ & $\mathbf{0 . 6 5}$ to 2.79 & 0.42 \\
\hline
\end{tabular}

Table 7. Changes in satisfaction with children-raising environment

\begin{tabular}{|c|c|c|c|}
\hline & 2019 & 2020 & $p$-value \\
\hline \multicolumn{3}{|c|}{ Satisfaction with her childcare environment } & 0.013 \\
\hline Satisfied & $238(57.8 \%)$ & $405(65.6 \%)$ & \\
\hline Unsatisfied & $174(42.2 \%)$ & $213(34.4 \%)$ & \\
\hline Total & $412(100 \%)$ & $618(100 \%)$ & \\
\hline
\end{tabular}


Table 8. Multivariate analysis of the correlation between the changes of her childcare during the COVID-19 lockdown and the mother's satisfaction with the childcare environment

\begin{tabular}{|c|c|c|c|}
\hline Covariate & $\begin{array}{l}\text { Hazard } \\
\text { Ratio }\end{array}$ & 95\% C.I. & $p$-value \\
\hline Anxiety about COVID-19 & 1.08 & 0.52 to 2.23 & 0.84 \\
\hline Partner working at home & 1.02 & 0.62 to 1.69 & 0.94 \\
\hline Economic anxiety & 0.45 & 0.24 to 0.83 & 0.01 \\
\hline $\begin{array}{l}\text { The presence of someone who } \\
\text { was helping raise the child }\end{array}$ & 2.79 & 1.66 to 4.67 & 0.0001 \\
\hline $\begin{array}{l}\text { The presence of someone who } \\
\text { could be easily consulted }\end{array}$ & 3.63 & 2.02 to 6.51 & $<0.0001$ \\
\hline
\end{tabular}




\section{Figures}

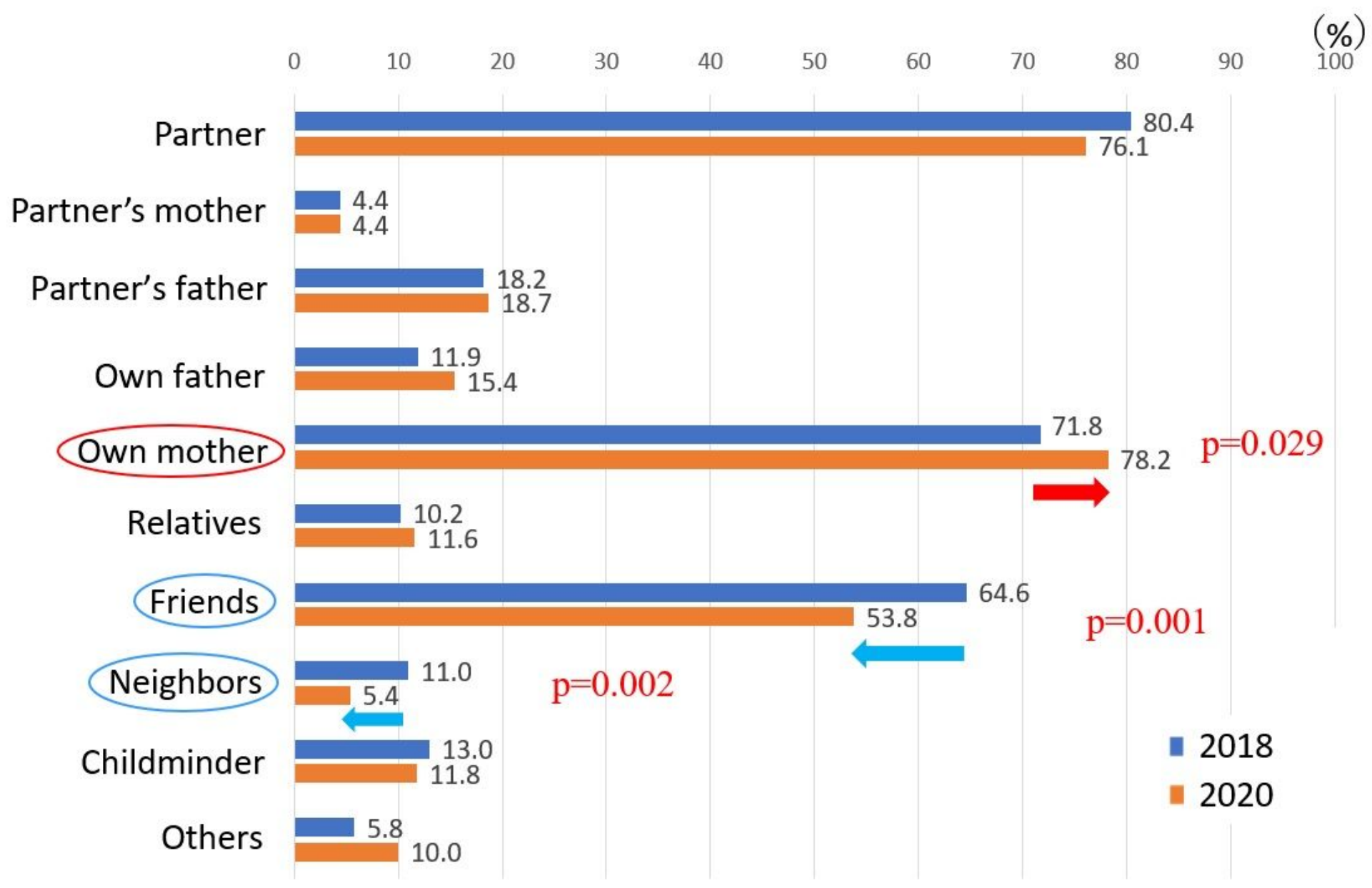

Figure 1

Whom she consult with about raising her child Back in $2019,71.8 \%$ of the mothers answered that they consulted with their mother; in 2020 , now $78.2 \%$ gave that answer, which was a significant increase $(p=0.029)$. In $2019,64.6 \%$ of the mothers consulted with their friends, whereas $53.8 \%$ gave that answer in 2020 , a significant decrease $(p=0.001)$. In $2019,11.0 \%$ of mothers answered that they consulted with their neighbors, but in 2020 it was only $5.4 \%$ of the answers, a significant decrease $(p=0.002)$. 